\title{
Chemotypic Comparison of AFLP Analyzed Indian Peppermint Germplasm to Selected Peppermint Oils of Other Countries
}

\author{
Ajit K. Shasany, Soni Gupta, Mahesh K. Gupta, Anil K. Singh, Ali A. Naqvi and \\ Suman P. S. Khanuja* \\ Central Institute of Medicinal and Aromatic Plants, Lucknow, India-226015
}

\begin{abstract}
Essential oil components of 20 Indian peppermint accessions were analyzed through GC and GC/MS and compared with the reported components found in oil samples of different countries (22 locations of 19 countries) to check the commercial potential of the germplasm collection. The comparative oil component analyses revealed the close relation of P4 and P5 (Indian collections) with Chinese and P9 to Japanese peppermint. Some of the analyzed samples (P6, P8, P11 and P17) were close to American, Canadian, European and South African oils. Essential oil profiles of Indian accessions P10, P14, P19 and P20 were quite different from others as revealed by component plot analysis. In addition to the similarities, distinct chemotypes in the germplasm were detected with unique essential oil component profiles, which have been discussed in details in this investigation. Further, Amplified fragment length polymorphism (AFLP) analysis of these 20 Indian accessions differentiated them genetically with a diversity ranging
between $17-95 \%$.
\end{abstract}

\section{Key Word Index}

Mentha x piperita, Lamiaceae, peppermint, essential oil composition, limonene, menthone, menthofuran, menthol, pulegone, menthyl acetate.

\section{Introduction}

Peppermint (Mentha x piperita), one of the hybrids of Mentha, is an important essential oil yielding crop of the Lamiaceae family. The oil and its constituents have been used since time immemorial as a flavoring agent as well as for its medicinal properties. The popularity of the plant gained momentum slowly from the herbal gardens of monasteries and churches in the medieval age through the kitchen gardens in the nineteenth century, to its present day large-scale cultivation and commercial production of the essential oil, which is variously used in the cosmetics, pharmaceuticals, food, confectionery and liquor industries ( 1 ). It is native of Mediterranean region, but the distillation of mint to produce an oil was started in England in 1750, where it was cultivated in herb gardens in Mitcham (Surrey). From England, it spread to other European countries and was introduced to the United States in 1790 . The cultivars of peppermint grown today in various European countries (Bulgaria, France, Hungary, Italy, Poland, Spain, former Yugoslavia), Argentina, former USSR, and the United States are the descendants of the English black mint (2). These cultivars have been developed through the acclimatization of the originally introduced English mint at various locations resulting in the altered oil profile as compared to its progenitor.
Presently, the conservation of the available biodiversity and its proper documentation and authentication has been given a lot of impetus. This available biodiversity can be exploited in generating high yielding varieties with better agronomic traits/ desired pool of secondary metabolites. Taking this in view, the Indian peppermint germplasm was analyzed genetically by amplified fragment length polymorphism (AFLP) to develop molecular markers for the authentication of the genotypes which can be exploited in future for variety development initiatives. The chemotypic profiles of these genotypes were compared with those from other countries as reported in literature to assess the tendencies of these chemotypes towards peppermint of other countries with an objective to assess the commercial potential.

\section{Experimental}

Plant material: The germplasm accessions (P1-P20) of Mentha $\mathrm{x}$ piperita were maintained at the National Gene Bank for Medicinal and Aromatic Plants (sponsored by Department of Biotechnology, Government of India) established at Central Institute of Medicinal and Aromatic Plants (CIMAP), Lucknow $\left(26.50^{\circ} \mathrm{N}, 81.01^{\circ} \mathrm{E}\right)$, India. The germplasm consisted of collections from the wild as well as selected genotypes from 
open pollinated seed progenies deposited by breeders of CIMAP from time to time (Table I). The runners (vegetative propagules) of these 20 genotypes were planted in plots of size $5 \mathrm{~m} \mathrm{x} 5 \mathrm{~m}$ at a row-to-row distance of $60 \mathrm{~cm}$ in the experimental field of CIMAP in the month of January 2001. Standard agronomic practices were followed for the cultivation of these genotypes.

Amplified fragment length polymorphism: Fresh leaf tissues from field grown plants were taken and DNA was isolated by the earlier described protocol of Khanuja et al. (3). The DNA quality and yield estimation was carried out by agarose gel electrophoresis as well as by florometry using DyNa Quant 200 Florometer (Hoefer), respectively. Five hundred ng of genomic DNA of each of these 20 peppermint accessions were taken for carrying out AFLP analysis, which was performed as reported by Shasany et al. and Vos et al. $(4,5)$. The four primer pairs MseI-CAG/ EcoRI- ACA; MseICTA/ EcoRI-AGC; MseI-CTC/EcoRI-ACA and MseI- CTG/ EcoRI-AGG were selected on the basis of maximum response to genus Mentha in "Explorer" gel. These primers were used to selectively amplify the 20 accessions of Mentha x piperita taken in the study. The AFLP amplification modules and the guidelines supplied by the manufacturer(PE Biosystems) were used for setting up the AFLP reactions.

AFLP data analysis: The peak analysis of the raw AFLP data was carried out by Gene Scan Analysis software v 3.1 (PE Biosystems). The presence and absence of bands were scored, pairwise genetic distances were calculated by Jaccard's coefficient (6) and the data were converted to similarity matrices using SPSS software (release 7.5.1) for windows (SPSS Inc., Chicago, IL; http://www.spss.com/). These similarity coefficients were used to generate a tree for cluster analysis by UPGMA method using NTSYS 2.1.

Oil isolation: Fresh herb samples (200 g) of each genotype were collected randomly 110 days after planting, from field-grown plants and subjected to hydrodistillation in Clevenger-type apparatus for $2 \mathrm{~h}$. Hydrodistillation was performed in triplicates for each of the samples. The oil samples were collected and stored in sealed glass vials at $4^{\circ} \mathrm{C}$ till further analysis.

Gas chromatography: The quantitative analysis of the oil samples was accomplished on "Autosystem XL" (FID) gas chromatograph fitted with a PE-5 column $(50 \mathrm{~m} \times 0.32 \mathrm{~mm} \times$ $0.25 \mu \mathrm{m}$ film thickness). The injector and detector temperature was maintained at $250^{\circ} \mathrm{C}$ and $300^{\circ} \mathrm{C}$, respectively. The oven temperature was programmed as: $1.5 \mathrm{~min}$ initial hold at $100^{\circ} \mathrm{C}$ followed by an increase of $3^{\circ} \mathrm{C}$ per min to $280^{\circ} \mathrm{C}$. The inlet pressure was $10 \mathrm{psi}$ and $\mathrm{He}$ was used as carrier gas at a rate of $1 \mathrm{~mL}$ per min; $0.2 \mu \mathrm{L}$ sample was injected in a split mode (1:10).

Gas chromatography/mass spectrometry: Turbomass with Autosystem XL GC (Perkin Elmer) was used for carrying out GC/MS analysis of the essential oil samples. Similar column and running conditions were used for mass analysis as in GC. The mass spectra were recorded in a scan mode in the range of $40-400 \mathrm{amu}$ at ionization energy of $70 \mathrm{eV}$.

Identification of oil components: Components of the oil were identified by, a) identical GC retention times of known samples (7), b) comparison of their retention indices, calcu-
Table I. Origin of the peppermint accessions used in the study

\begin{tabular}{lll}
\hline S.No. & Accession & Origin/Source \\
\hline 1 & P1 & Collection from Lucknow, Uttar Pradesh \\
2 & P2 & Gene Bank accession, CIMAP \\
3 & P3 & Selection from P1 \\
4 & P4 & Seedling from seeds of P3 \\
5 & P5 & Collection from Badaun, Uttar Pradesh \\
6 & P6 & Collection from Badaun, Uttar Pradesh; \\
& & released as 'Madhuras' \\
7 & P7 & Collection from Badaun, Uttar Pradesh \\
8 & P8 & Mutant of P11 \\
9 & P9 & Mutant of P11 \\
10 & P10 & Mutant of P11 \\
11 & P11 & 'Kukrail', a released variety from CIMAP \\
12 & P12 & 'Tushar', a released variety from CIMAP \\
13 & P13 & 'Pranjal', a released variety from CIMAP \\
14 & P14 & Gene Bank accession, CIMAP \\
15 & P15 & Gene Bank accession, CIMAP \\
16 & P16 & Collection from Palampur, Himachal Pradesh \\
17 & P17 & Gene Bank accession, CIMAP \\
18 & P18 & Gene Bank accession, CIMAP \\
19 & P19 & Collection from Uttaranchal \\
20 & P20 & 'Indus', a released variety from CIMAP \\
& & \\
\hline
\end{tabular}

lated by injection of a series of $\mathrm{n}$-alkanes and c) matching of the obtained mass spectral patterns with those in the in-built libraries (NIST, Wiley, NBS) in the spectrometer database. Quantification of the oil components were performed on the basis of GC peak area representing the percent of particular oil constituent which was recorded and used for chemotypic characterization of the germplasm. The data shown are mean value of three injections.

Statistical data analysis: The oil components of twenty Indian genotypes were compared with those reported from 22 locations of 19 countries (Argentina, Australia, Bulgaria, Canada, China, France, Hungary, India, Italy, Japan, Morocco, New Zealand, Poland, South Africa, Spain, United Kingdom, former USSR, former Yugoslavia, United States) spanning six continents (8). Based on the content of the oil components distances were calculated using Pearson's correlation and converted to similarity coefficients, which was used to construct a cluster tree using NTSYS v2.02. Principal component analysis was applied for comparative study of the analyzed Indian oil samples with those from other countries using SPSS software.

\section{Results and Discussion}

Genetic diversity by AFLP analysis: A total of 580 fragments were scored by AFLP analysis representing 403 polymorphic and 177 unique AFLP loci. Maximum numbers of fragments were generated by the primer combination MseICTC/EcoRI-ACA (203) followed by the combinations MseICTG/ EcoRI-AGG (193), MseI-CAG/ EcoRI-ACA (152) and MseI-CTA/ EcoRI-AGC (32). Within these genotypes $69.48 \%$ polymorphism and $30.51 \%$ uniqueness was detected. The differences among these genotypes vary within a wide range $(17-95 \%)$ with a similarity range of 5-83\% (Table II). 


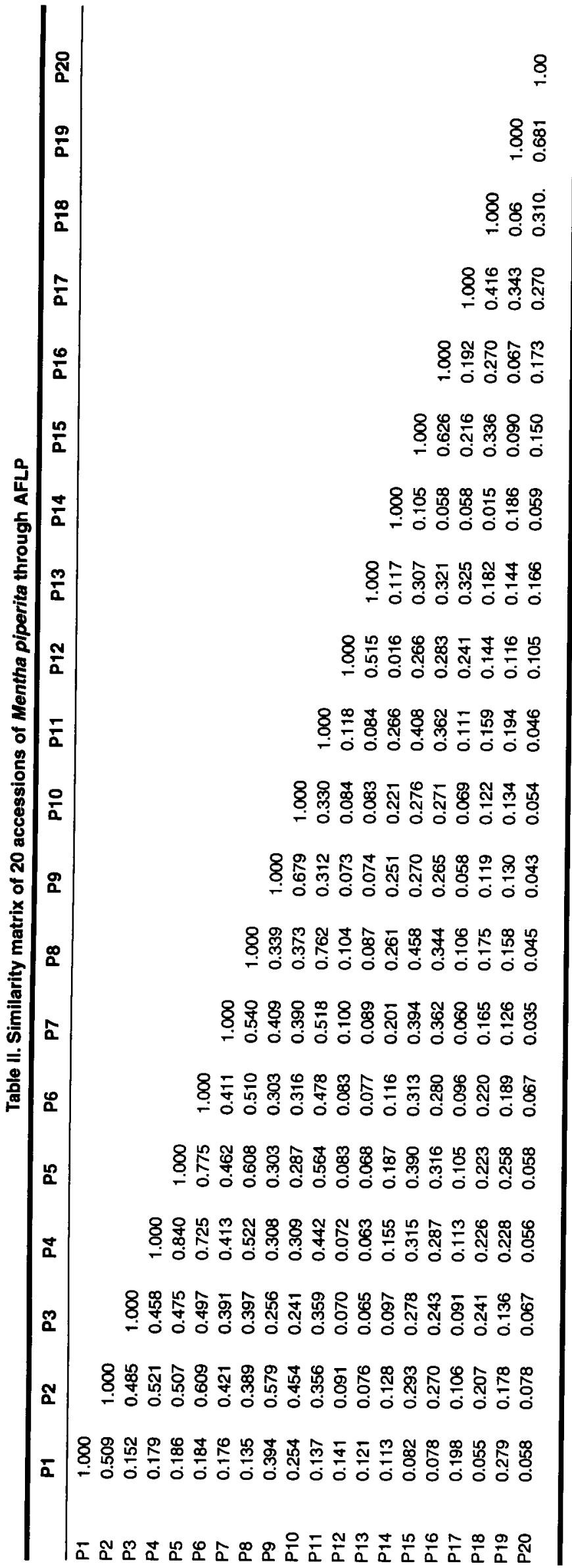

The clustering pattern distributed these accessions in two major groups (Figure 1). The bigger group consisted of accessions P1, P2, P3, P4, P5, P6, P7, P8, P9, P10, P11, P14, P15, $\mathrm{P} 16$ and $\mathrm{P} 19$, where $\mathrm{P} 14$ outgrouped from the rest. $\mathrm{P} 4$ and $\mathrm{P} 5$ were very closely related along with P6 in the same cluster and $\mathrm{P} 2$ as an offset. Maximum similarity was seen between accessions, P4 and P5 (83\%). All these (P2, P4, P5 and P6) form a small subcluster from which P3 outgrouped as a separate entity. The other smaller subgroup consisted of P8 and P11 (sharing a similarity of $69.7 \%$ ), which were very close to each other with another offset of $\mathrm{P} 7$ in this subgroup. The accessions $\mathrm{P} 9$ and $\mathrm{P} 10$ (54.3\% similarity) clustered togetherwhereas P15 and P16 (69.4\% similarity) grouped together separately. Though the accessions $\mathrm{P} 1$ and P19 genotypically clustered together but were $72 \%$ different and were an out-group of all above described accessions. In the other cluster P12 and P13 (53.3\% similarity) were related followed by P17 and P18 (43.9 $\%$ similarity). P20 was outgrouped from the cluster, which also contains the accessions P17 and P18.

Comparative chemotypic profiling and unique representative AFLP markers: Analysis of oil samples of the twenty Indian peppermint accessions based on fourteen identified essential oil components profiled, compared and enlisted in Table III. The oil of accession P10 comprised the highest amount of $\alpha$-pinene, sabinene, $\beta$-pinene, limonene and $\gamma$-terpinene as compared to all other accessions. On the other hand the lowest amount of sabinene, $\beta$-pinene, limonene, 1,8 cineole, $\gamma$-terpinene, menthofuran and piperitone was recorded in accession P9. Conversely, this genotype accumulated the maximum amount of menthol in its oil. The two accessions, $\mathrm{P} 19$ and P20 varied from other accessions by the presence of highest amount of pulegone ( $14.28 \%$ and $15.41 \%$, respectively) and menthofuran $(27.33 \%$ and $27.25 \%$, respectively $)$ and least amount of menthone $(2.03 \%$ and $1.97 \%$, respectively) in their oil. The finest of all peppermint oils, English (Mitcham), is characterized by its sweet odor and strong flavor, which is a result of high content of total and free menthol, and usually a low content of menthone and resins (2). Menthol to menthone ratio was greater than 1.0 as seen in accessions $\mathrm{P} 6, \mathrm{P} 7, \mathrm{P} 8, \mathrm{P9}$, $\mathrm{P} 10, \mathrm{P} 11, \mathrm{P} 14, \mathrm{P} 16, \mathrm{P} 17, \mathrm{P} 18, \mathrm{P} 19$ and 20 whereas it was less then 1 as observed in accessions P1, P2, P3, P4, P5, P12, P13 and P15. The comparative study of the essential oil composition from different countries, as reported by Lawrence (8), revealed menthol to menthone ratio greater than 1.0 in oils of all countries except those from China, Poland and Spain. The 20 peppermint accessions studied exhibited varying amounts of oil components pointing at the differing oil biosynthetic capabilities due to differences at the genotypic level leading to chemotypic diversity. The similarity of the oil component profiles of these peppermint accessions with those from other countries was further studied by principal component analysis (Fig 2-5). The amounts of 14 oil components of 20 peppermint accessions together with those of other 22 reported oil samples from different locations (8) were used for the analysis. Principal component analysis showed the clustering of these samples into eight clusters. These clusters could be easily differentiated from each other on the basis of menthol to menthone ratio in their oils (Table IV). The accessions, P19 and P20, clustered together with a high percentage of pulegone and menthofuran in its 
oil (cluster I) (Figure 2). As indicated in Table IV, 14 unique AFLP marker fragments only present in these two accessions were obtained with three primer combinations. Accession P9 and Japanese oil clustered together (cluster II) (Figure 3) and showed highest menthol content. P9 showed eight unique marker fragments with three primer combinations (Table IV). On the basis of oil components, Argentina, Bulgaria, France,

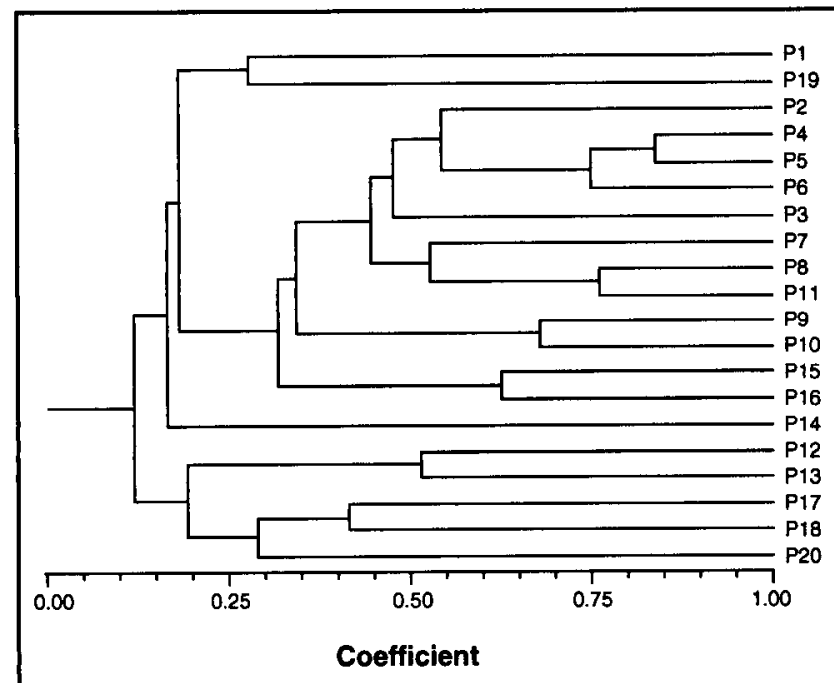

Figure1. Clustering of 20 peppermint oil accessions after AFLP analysis
Italy, New Zealand, US (Kenewick), and former USSR clustered together (cluster III) [2.43-2.84 menthol to menthone ratio] whereas Australia, Morocco, US (Idaho), US (Willamette Valley) and UK grouped together forming cluster IV (Figure 3) [2.10-2.27 menthol to menthone ratio]. Canadian, Hungarian, Spanish, US (Midwest), former Yugoslavian and South African oils grouped together with Indian peppermint oils of P6, P8, P1l and P17 forming cluster V. The oils in this cluster demonstrated menthol to menthone ratio of $1.26-1.66$ and the AFLP analyzed Indian accessions of this cluster showed two unique marker fragments of 101 and $131 \mathrm{bp}$ with two of the primer combinations (Table IV). The Indian oil [as reported by Lawrence (8)] clustered with P7, P16 and P18 oils forming cluster VI (Figure 4). The menthol to menthone ratio of the oils in this cluster was in the range of 1.04-1.11 and two unique marker fragments were obtained for AFLP analyzed Indian accessions. Polish oil grouped with the Indian peppermint oils of P1, P2, P3, P12, P13 and P15 (Cluster VII) (Figure 5) sharing menthol to menthone ratio less than one (0.74-0.95). Chinese oil showed a close relationship with the oils of P4 and P5 (cluster VIII) (Figure 5) with least menthol to menthone ratio in the range of $0.48-0.66$. Maximum number of unique AFLP marker fragments (79) was obtained for accessions P4 and $P 5$ belonging to this cluster. Oils of peppermint accessions P10 and P14 separated from other clusters (Figure 2) with differential amounts of oil components. Five and 25 AFLP fragments were obtained in outgrouped accessions P10 and P14, respectively (Table IV).

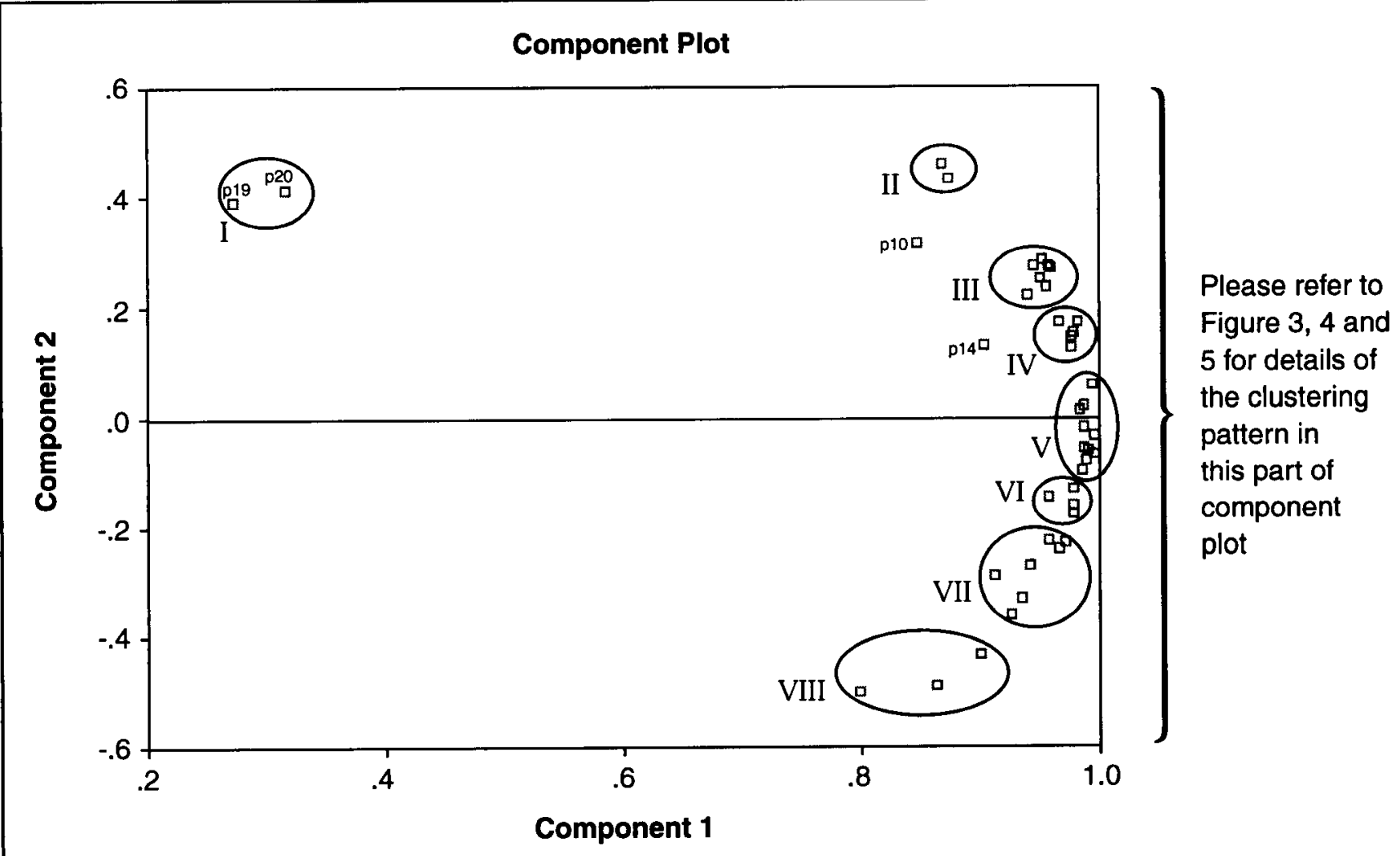

Figure 2. Principal component analysis of peppermint oil samples from different countries [P10, P14, P19 and P20-peppermint accessions at CIMAP, Lucknow, India] 

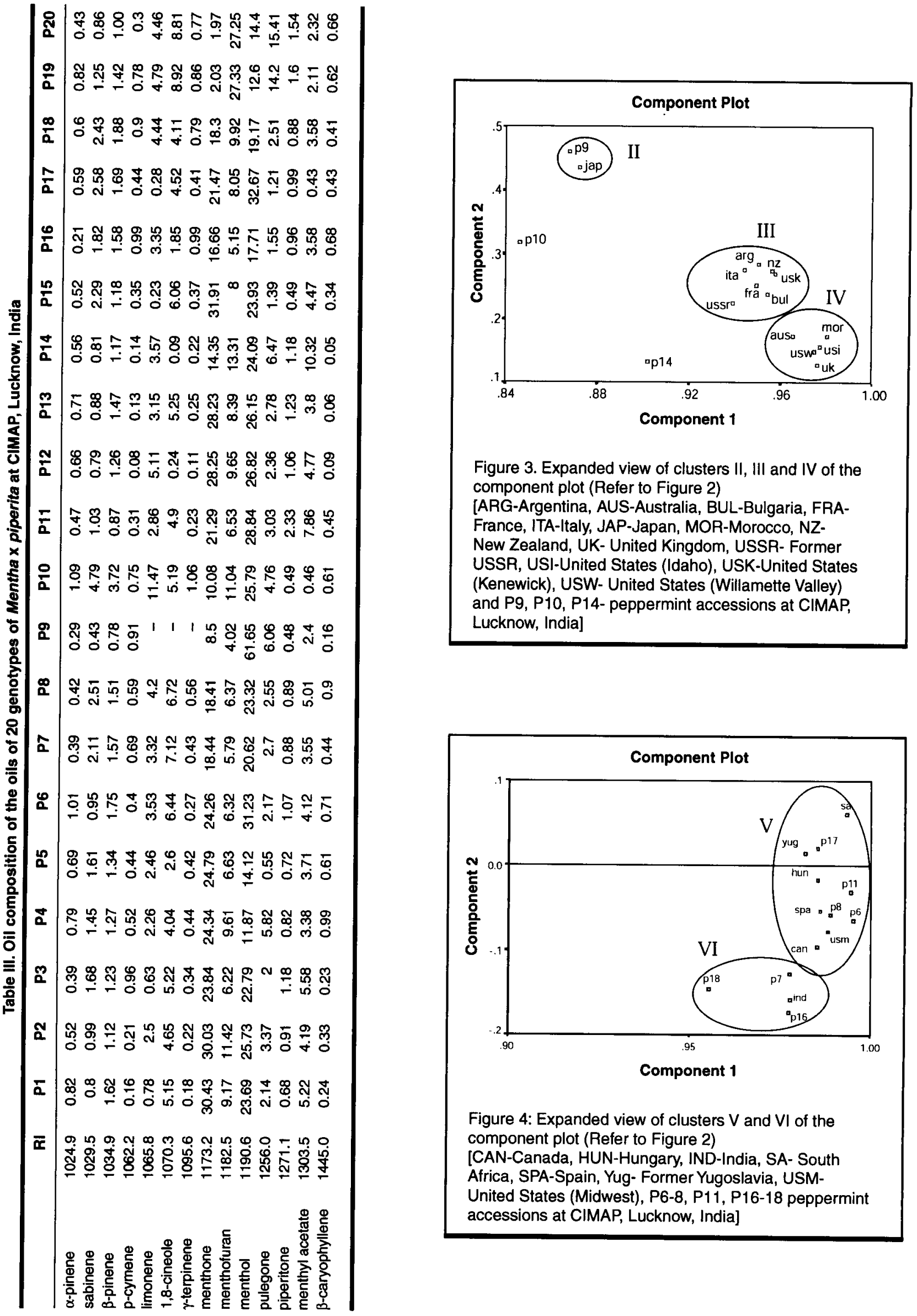


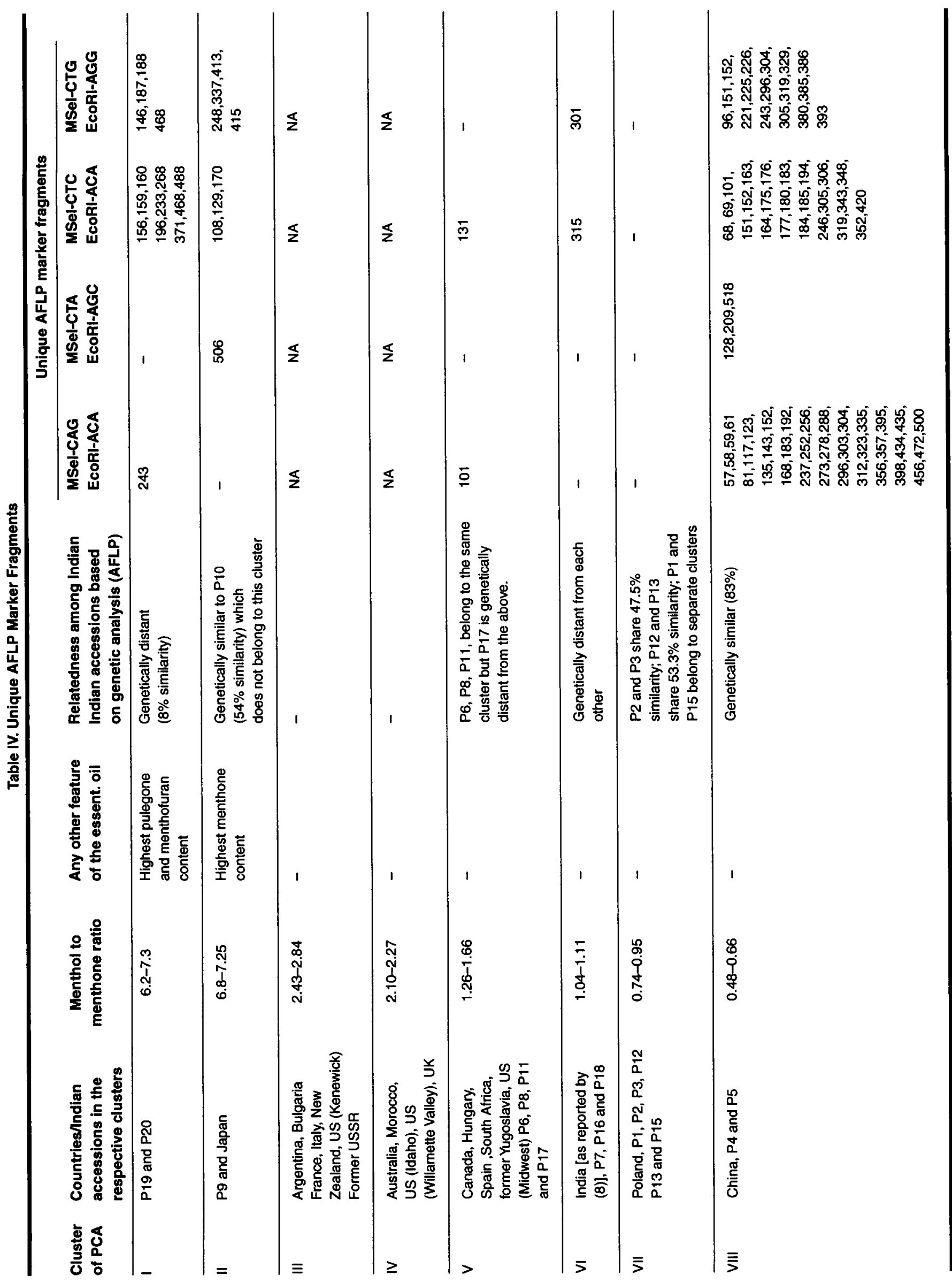



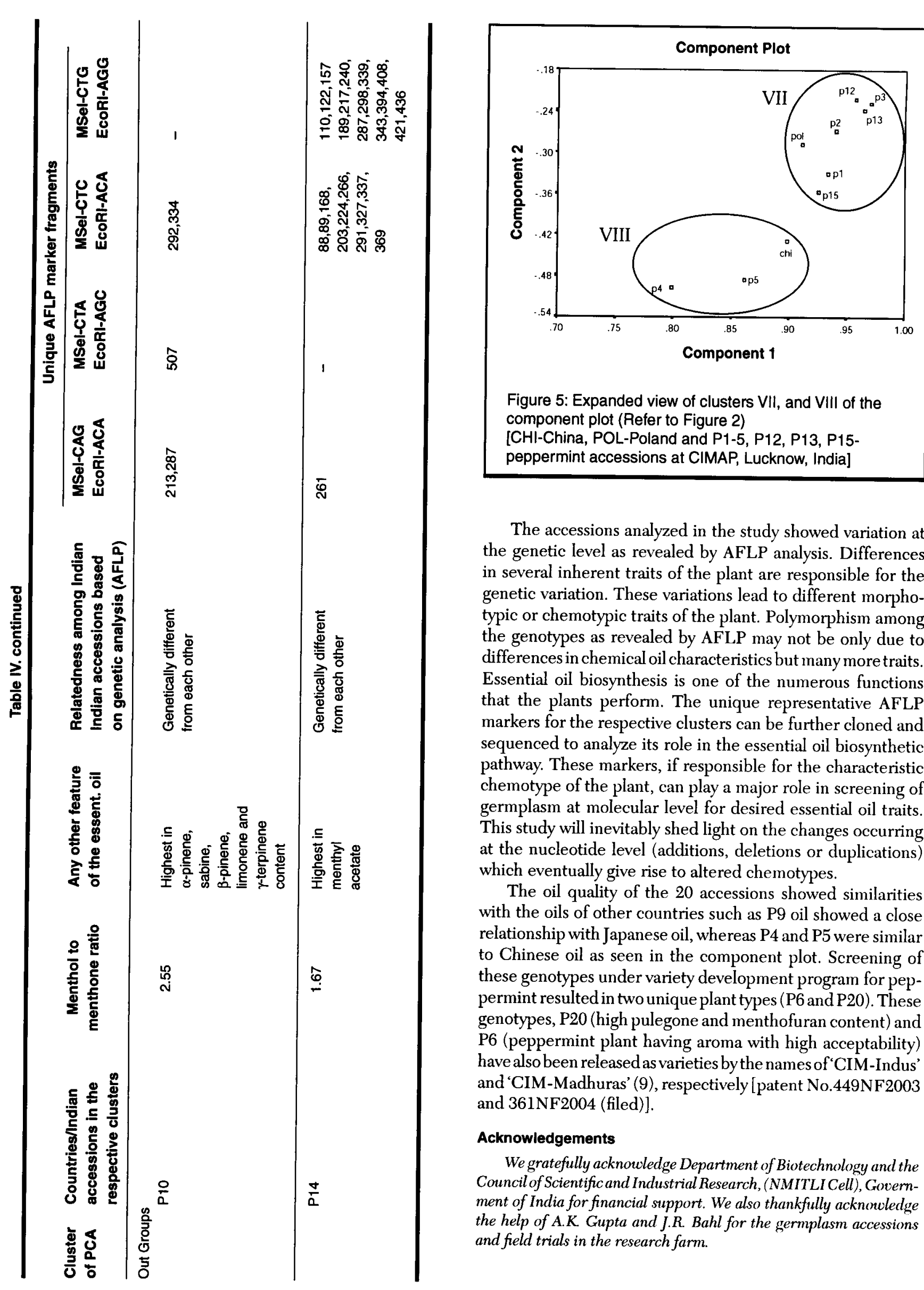

Figure 5: Expanded view of clusters VII, and VIII of the component plot (Refer to Figure 2)

[CHI-China, POL-Poland and P1-5, P12, P13, P15-

peppermint accessions at CIMAP, Lucknow, India]

The accessions analyzed in the study showed variation at the genetic level as revealed by AFLP analysis. Differences in several inherent traits of the plant are responsible for the genetic variation. These variations lead to different morphotypic or chemotypic traits of the plant. Polymorphism among the genotypes as revealed by AFLP may not be only due to differences in chemical oil characteristics but many more traits. Essential oil biosynthesis is one of the numerous functions that the plants perform. The unique representative AFLP markers for the respective clusters can be further cloned and sequenced to analyze its role in the essential oil biosynthetic pathway. These markers, if responsible for the characteristic chemotype of the plant, can play a major role in screening of germplasm at molecular level for desired essential oil traits. This study will inevitably shed light on the changes occurring at the nucleotide level (additions, deletions or duplications) which eventually give rise to altered chemotypes.

The oil quality of the 20 accessions showed similarities with the oils of other countries such as P9 oil showed a close relationship with Japanese oil, whereas P4 and P5 were similar to Chinese oil as seen in the component plot. Screening of these genotypes under variety development program for peppermint resulted in two unique plant types ( $\mathrm{P} 6$ and $\mathrm{P} 20)$. These genotypes, P20 (high pulegone and menthofuran content) and P6 (peppermint plant having aroma with high acceptability) have also been released as varieties by the names of 'CIM-Indus' and 'CIM-Madhuras' (9), respectively [patent No.449NF2003 and 361NF2004 (filed)].

\section{Acknowledgements}

We gratefully acknowledge Department of Biotechnology and the Council of Scientific and Industrial Research, (NMITLI Cell), Government of India for financial support. We also thankfully acknowledge the help of A.K Gupta and J.R. Bahl for the germplasm accessions and field trials in the research farm. 


\section{References}

1. A. Husain, Essential Oil Plants and their Cultivation. Central Institute of Medicinal and Aromatic Plants (Council of Scientific and Industrial Research) India (1994).

2. E. Guenther, The Essential Oils. Vol.III D. Van Nostrand, Inc. Princeton, NJ (1961).

3. S.P.S. Khanuja, A.K.Shasany, M.P. Darokar and S. Kumar, Rapid isolation of DNA from the dry and fresh samples of plants producing large amounts of secondary metabolites and essential oils by modified CTAB method. Plant Mol. Biol. Rep., 17, 74.

4. A.K.Shasany, M.P.Darokar, S.Dhawan, A.K.Gupta, S.Gupta, A.K.Shukla, N.K. Patra, S.P.S. Khanuja, Co-inheritance of RAPD and AFLP Markers Developed In Intra and Interspecific Hybrids of Mentha. J. Heredity (2005) (In Press).

5. P. Vos, R Hogers, M. Bleeker, M. Reijans, T .van de Lee, M. Hornes, A. Frijters, J. Pot, J. Peleman, M. Kulper and M. Zabeau, AFLP: a new technique for fingerprinting. Nucleic Acids Res., 23, 4407-4414 (1995).
6. P.Jaccard, Nouvelles reserches surla distribution florae. Bull. Soc. Vaudoise Sci. Naturel., 44, 223-270 (1908)

7. W.Jenningsand T.Shibamoto, Quantitative Analysis of FlavorandFragrance Volatiles by Capillary Gas Chromatography. Academic Press, New York, NY (1980)

8. B.M. Lawrence, Progress in Essential oils. Perfum. Flavor., 18 (4), 59-71 (1993).

9. S.P.S. Khanuja, A.K.Shasany, A. Kalra, N.K. Patra, M.P. Darokar, T Padmapriya, S.Gupta, R.K.Upadhaya, M.K.Gupta, A.K.Singh, A.A. Naqvi, A.K. Singh, V.K.S. Tomar, J.R. Bahi, R.K. Lal, R.P. Bansal, A Krishna and D. Kumar, A sweet smelling peppermint plant, 'CIM-Madhuras.' J. Med. Arom. Plant Sci., 26, 790-794 (2004). 


\section{COPYRIGHT INFORMATION}

TITLE: Chemotypic Comparison of AFLP Analyzed Indian Peppermint Germplasm to $\mathrm{S}$

SOURCE: Journal of Essential Oil Research 19 no2 Mr/Ap 2007

PAGE(S): $138-45$

The magazine publisher is the copyright holder of this articleand it is reproduced with permission. Further reproduction of this article in violation of the copyright is prohibited. 